\title{
Non-syndromic aortic valve myxoma in a teen, cause of angina symptoms
}

\author{
Geoffrey Joseph Changwe, Tao Zhang, Haizhou Zhang ${ }^{*}$ and Chengwei Zou
}

\begin{abstract}
Background: Cardiac myxoma, a common benign primary tumor of the heart can be categorized into syndromic (Carney Complex) and non-syndromic(isolated). Carney Complex associated myxomas can be found in any region and system (cardiac, cutaneous, osseous, genitalia), and may manifest at a tender age. On the contrary, non-syndromic cardiac myxomas are usually confined to the chambers, and symptoms often present from 5 th decade of life. Aortic valve myxoma is a very unusual occurrence, and presentation in a teen is extremely rare.

Case report: We share a case of aortic valve myxoma, uncovered using echocardiography in a 16-year-old male, admitted with complaints of exertional chest pain, dyspnoea and systolic murmur. Patient underwent uneventful surgery for tumor excision, and discharged 6-days post operation.

Conclusion: Given the high risk of developing cardiogenic stroke, infective endocarditis, degenerative effects on aortic valve leaflets and possible sudden death, like many other centers, we advocate for immediate liquidation of aortic myxoma regardless of age and symptoms.
\end{abstract}

Keywords: Cardiac myxoma, Aortic valve myxoma, Non-syndromic, Carney complex

\section{Background}

Aortic valve myxomas are a very rare finding of the nonsyndromic primary benign cardiac tumors, and presentation in teen patients is extremely unusual. If not liquidated on time can cause a spectrum of complications [1-4] and sudden death.

\section{Case presentation}

A 16-year-old male patient presented to our cardiology department with a 4-month history of exertional chest pain and dyspnea. It is alleged that, sometime in March, 2018, the patient suffered from a 'common-cold', which presented in form of chest pain and high body temperature. Despite having undergone standard treatment and complete liquidation of both fever and chest pain at rest, any physical stress begun eliciting chest pain. On physical examination of the skin and genitalia excluded features associated with Carney Complex [3], while, auscultation revealed a systolic murmur in the 2nd right intercostal pace, which slightly muffled upon

\footnotetext{
* Correspondence: zhz_doctor@163.com

Departments of Cardiovascular Surgery and Ultrasound, Shandong Provincial Hospital affiliated to Shandong University, Jingwu No. 324, 250021 Jinan, People's Republic of China
}

supine positioning. Clinical vitals at rest: $\mathrm{BP} 98 / 56 \mathrm{mmHg}$, pulse- $88 \mathrm{~b} / \mathrm{min}$, respirations rate- $18 \mathrm{~b} / \mathrm{min}$ and body temperature $36.7^{\circ} \mathrm{C}$. Transthoracic echocardiography uncovered a lingering mass (Fig. 1, Panel. A), and a diagnosis of suspected myxoma was recorded. Other imaging modalities were non-remarkable. Given the complaints, patient was categorized under NYHA Class II prior surgery.

The patient was wheeled in operation room on emergency basis, and under cardiopulmonary bypass machine, after aortotomy (Panel B) a solid gelatinous mass (Panel.C) with stalk attached to right coronary cusp edge was excised and retrieved. The aortic valve and adjacent structures were intact. The aortic cavity was washed with saline to ensure complete liquidation of clots, which could potentially occlude coronary ostia. Aortotomy and chest were closed in standard fashion with two drainage tubes inserted. Prior discharge, transthoracicechocardiography revealed no mass (Panel. D), and patient did not complain of exertional dyspnea apart from slight incisional tenderness. The morphological finding of aortic valve mass sample is reflected in Fig. 2. During his 2nd review, a month after operation, the patient had recovered and was re-categorized back to NYHA class I.

C The Author(s). 2019 Open Access This article is distributed under the terms of the Creative Commons Attribution 4.0 International License (http://creativecommons.org/licenses/by/4.0/), which permits unrestricted use, distribution, and reproduction in any medium, provided you give appropriate credit to the original author(s) and the source, provide a link to the Creative Commons license, and indicate if changes were made. The Creative Commons Public Domain Dedication waiver (http://creativecommons.org/publicdomain/zero/1.0/) applies to the data made available in this article, unless otherwise stated. 


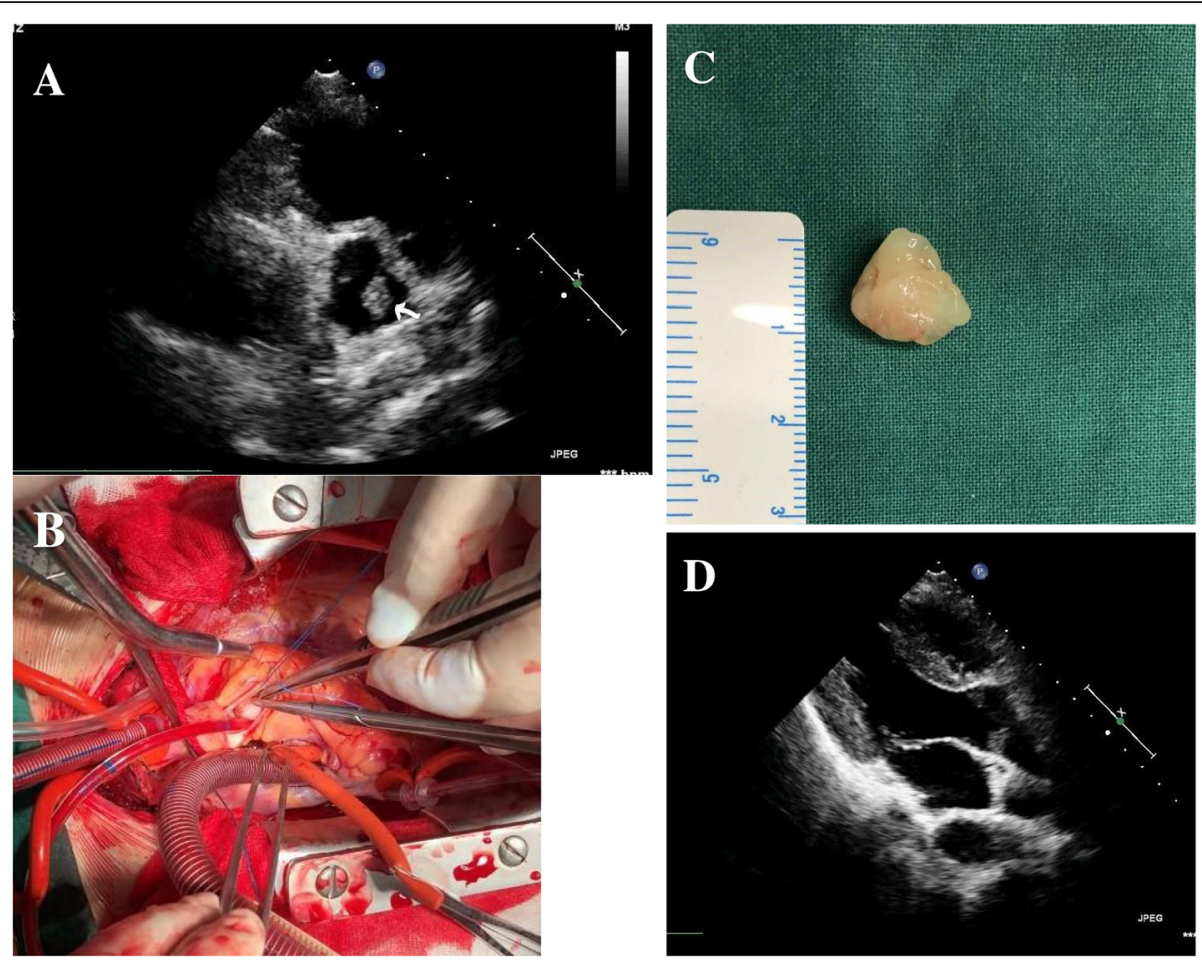

Fig. 1 Panels a \& d, pre/post operation echocardiography (white arrow-myxoma), b-aortotomy \& c-myxoma

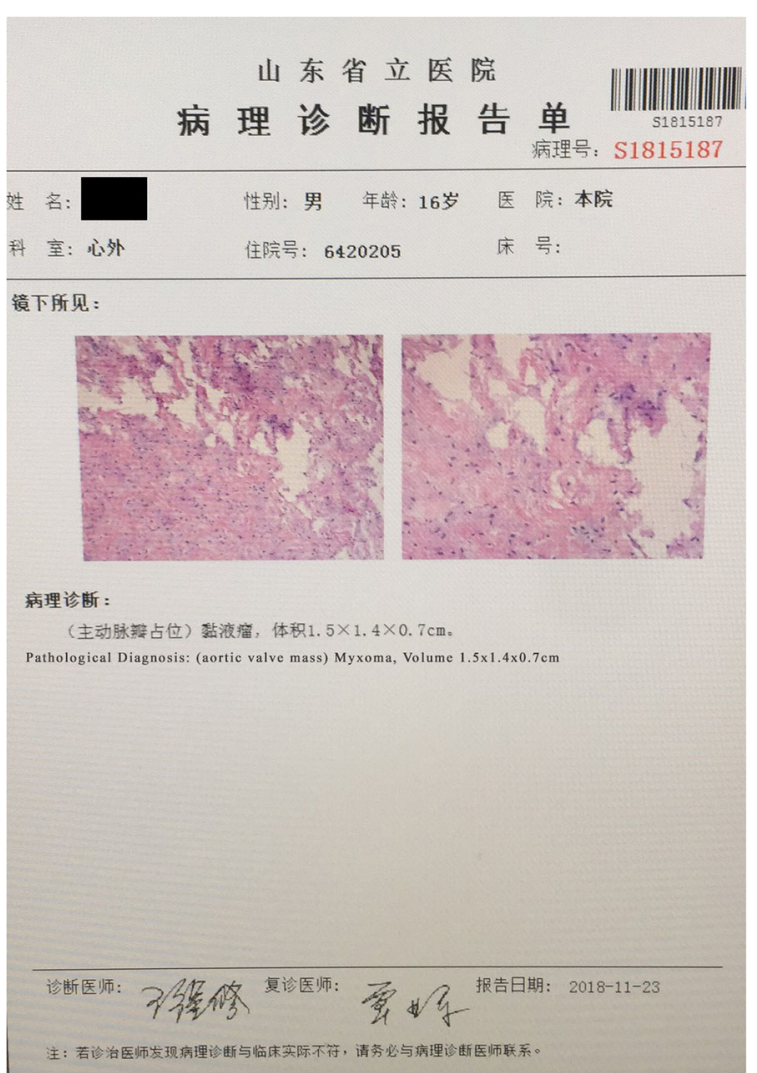

Fig. 2 Pathological [morphologic] report of aortic myxoma 


\section{Discussion}

Cardiac myxoma (CM), a common benign primary tumor of can be categorized into syndromic (Carney Complex) and non-syndromic(isolated). Carney Complex(CNC) associated myxomas can be found in any region and system (cardiac, cutaneous, osseous, genitalia), and may manifest at a tender age [3]. While, their counter-parts, are often confined to cardiac chambers [4, 5](LA-75\%, RA-18\%, L/ $\mathrm{R}-\mathrm{V}-6 \%$, valves $<1 \%)$.In addition, non-syndromic CM's are usually asymptomatic and their discovery often incidental $[6,7]$, with symptoms commonly manifesting from the 5 th decade of life. Aortic valve myxoma is a rare finding, and a symptomatic manifestation in a teen, as is our case is extremely unusual. In one major study of 61 cases of $\mathrm{CM}$, no single aortic case was isolated. However, manifestation symptoms (dyspnea-67\%, systolic murmur-49.2\%) at mean ages: 48.8 and 51.9 years in males and females were observed $[5,7]$.

Aortic valve myxoma associated complications and potentially fatal include cardiac outflow tract obstruction [1], embolic stroke [2, 3, 8] and myocardial infarction, infective endocarditis [7] and death [3, 5]. In one study of Cardiac related deaths of 29 patients with $\mathrm{CNC}, \mathrm{CM}$ accounted for $13(44.8 \%)$, and $6(20.7 \%)$ due to CM emboli [3].To the best of our knowledge, our case is 3rd case of the reported aortic valve myxoma in a teen.

\section{Conclusion}

In view of the above, and many other reports, we advocate for immediate liquidation of the lesion, and surgical approach carry minimal risks with best outcome.

\section{Abbreviations}

CM: Cardiac Myxoma; CNC: Carney Complex; L/R: Left/right ventricle; LA: Left atrium; NYHA: New York Heart Association; RA: Right atrium

\section{Acknowledgements}

We are grateful of the support from Shandong University.

\section{Authors' contributions}

GJC-concept, design of initial and final manuscript, TZ-data collection and curation, HZ-design and proof reading, CZ-proof reading and PAC provision. All authors read and approved the final manuscript.

Funding

National key R\&D program of China (2017YFC1308000).

Availability of data and materials

Available on appropriate request from author.

Ethics approval and consent to participate

Hospital Ethics committee approved publication.

Consent for publication

Patient was informed and written consent obtained.

Competing interests

The authors declare that they have no competing interests.
Received: 7 March 2019 Accepted: 17 July 2019

Published online: 23 July 2019

References

1. Prifti $E$, Ademaj $F$, Kajo E, Baboci A. A giant myxoma originating from the aortic valve causing severe left ventricular tract obstruction: a case report and literature review. World J Surg Oncol. 2015;13(1). http://www.wjso.com/ content/13/1/151. https://doi.org/10.1186/s12957-015-0575-9. Accessed 2 Feb 2019.

2. Koyalakonda SP, Mediratta NK, Ball J, Royle M. A rare case of aortic valve Myxoma: an unusual cause of embolic stroke. Cardiology. 2011;118(2):101-3. https://doi.org/10.1159/000327081.

3. Stratakis CA, Kirschner LS, Carney JA. Genetics of endocrine disease. J Clin Endocrinol Metab. 2001;86(9)4041-4046.

4. Kim HY, Kwon SU, Jang W-I, Kim H-S, Kim JS, Lee HS, Park MY, Kim T, Lee SY, Doh $\mathrm{JH}$, et al. A rare case of aortic valve Myxoma: easy to confuse with papillary Fibroelastoma. Korean Circ J. 2012;42(4):281. https://doi.org/10.4 070/kcj.2012.42.4.281.

5. Wang J-G, Li Y-J, Liu H, Li N-N, Zhao J, Xing X-M. Clinicopathologic analysis of cardiac myxomas: seven years' experience with 61 patients. J Thorac Dis. 2012;4(3):12.

6. Laguna G, Carrascal Y, Arce N, Martínez G. Incidental aortic valve myxoma: tumour excision and aortic valve repair. Eur J Cardiothorac Surg. 2015;48(3): 510-1. https://doi.org/10.1093/ejcts/ezu508.

7. Okamoto T, Doi H, Kazui T, Suzuki M, Koshima R, Yamashita T, Sugiki K, Ohno T. Aortic valve Myxoma mimicking vegetation: report of a case. Surg Today. 2006;36(10):927-9. https://doi.org/10.1007/s00595-006-3273-y.

8. Fernandez AL, Vega M, El-Diasty MM, Suarez JM. Myxoma of the aortic valve. Interact Cardiovasc Thorac Surg. 2012;15(3):560-2. https://doi.org/10.1 093/icvts/ivs117.

\section{Publisher's Note}

Springer Nature remains neutral with regard to jurisdictional claims in published maps and institutional affiliations.
Ready to submit your research? Choose BMC and benefit from:
- fast, convenient online submission
- thorough peer review by experienced researchers in your field
- rapid publication on acceptance
- support for research data, including large and complex data types
- gold Open Access which fosters wider collaboration and increased citations
- maximum visibility for your research: over 100M website views per year
At BMC, research is always in progress.
Learn more biomedcentral.com/submissions 